\title{
Shifts in average energy of deposited atoms by magnetron sputtering through modifications in anode geometry: a simulation study
}

\section{Mudanças na energia média dos átomos depositados por magnetron sputtering através de modificações na geometria do ânodo: um estudo computacional}

Júlia Karnopp ${ }^{1}$, Julio César Sagás ${ }^{1}$

\begin{abstract}
The deposition of titanium and gadolinium films by magnetron sputtering was simulated by using software SiMTra. The main goal is to analyze the average energy of deposited atoms as a function of argon pressure at different anode geometries. Two different anode configurations were used: a grid inserted between the target and the substrate, in the so-called grid-assisted magnetron sputtering, and a disk with different apertures. In the case of grid anode, simulations were also performed with a shutter in front of the substrate. The presence of the grid increases the average energy of atoms arriving at the substrate for pressures in the range between 1.0 and $8.0 \mathrm{~Pa}$. The disk anode also changes the average energy, but such effect depends on the size of aperture.
\end{abstract}

Keywords: Magnetron sputtering, Thin film deposition, SiMTra.

\section{RESUMO}

A deposição de filmes de gadolínio e titânio por magnetron sputtering foi simulada usando o programa SiMTra. O objetivo principal é analisar a energia média dos átomos depositados em função da pressão de argônio para diferentes geometrias do ânodo. Duas configurações diferentes de ânodo foram utilizadas: uma tela inserida entre o alvo e o substrato, no chamado gridassisted magnetron sputtering e um disco com diferentes aberturas. No caso da tela, as simulações foram realizadas também incluindo um anteparo em frente ao substrato. A presença da tela aumenta a energia média dos átomos chegando ao substrato para pressões entre 1,0 e 8,0 Pa. O ânodo na forma de disco também altera a energia média, mas o efeito depende do tamanho da abertura.

Palavras-chave: Magnetron sputtering, Deposição de filmes finos, SiMTra.

'Universidade do Estado de Santa Catarina - Centro de Ciências Tecnológicas - Departamento de Física - Joinville/SC - Brazil. Correspondence author: Julio César Sagás | Universidade do Estado de Santa Catarina - Centro de Ciências Tecnológicas - Departamento de Física Laboratório de Plasmas, Filmes e Superfícies | Rua Paulo Malschitzki, 200 | CEP 89.219-710 - Joinville/SC - Brazil | E-mail: julio.sagas@udesc.br Received: Apr. 4, 2018 | Approved: May 29, 2018 


\section{INTRODUCTION}

Thin film deposition is a technique to modify a series of surface properties, including electrical, mechanical, magnetic, and optical ones. Among the deposition techniques, a remarkable one is the magnetron sputtering deposition, due to the control of deposition parameters and to the high energy of deposited atoms, if compared to techniques such as evaporation. The film properties depend on the deposition conditions, particularly on the energy transfer to substrate ${ }^{1}$, which can be changed according to the desired properties. The total energy transfer is a function of several parameters, such as the radiation received from the wall and from the plasma, the charged particle bombardment and the flux of atoms to the substrate. Among these parameters, the energy of the deposited atoms has received little attention in the literature. This parameter can interfere in the film characteristics, as structure, density ${ }^{2}$, and in the interface mixing ${ }^{3}$.

A variation of the magnetron sputtering system is the gridassisted magnetron sputtering. In this system, a grounded grid is inserted close to target. The grid is the discharge anode and increases the plasma confinement, resulting in a more stable discharge $e^{2,4-6}$, as well as decreases the hysteresis in reactive sputtering ${ }^{4,7}$. The size, position and geometry of anode have strong influence on the plasma properties ${ }^{8}$, but little attention has been paid to an occasional variation in the deposited atoms energy.

Among the computational tools to calculate the energy of deposited atoms, the literature highlights those based on Monte Carlo method, as the free software SiMTra (Simulation of Metal Transport) developed by research group Draft from Ghent University ${ }^{9,10}$. The SiMTra describes the transport of the sputtered particles through a gas phase in a vacuum chamber. From the initial conditions of sputtered atoms ${ }^{11}$, the particles trajectories are described individually. As a result, the software reports the energy and the incident angle ${ }^{12,13}$ of atoms hitting a surface, as well the fraction of deposited atoms in any surface ${ }^{14}$, including the target ${ }^{15}$.

In order to study the energy of metal atoms arriving at the substrate, simulations were done using the software SiMTra. The energy was analyzed for the grid assisted system and using a disk anode with different apertures. In the case of grid-assisted magnetron, simulations were also done using a shutter in front of the substrate.

\section{METHOD}

The simulations were carried out for gadolinium (Gd) and titanium ( $\mathrm{Ti}$ ) targets in argon (Ar) atmosphere in the pressure range between 0.0 and $10.0 \mathrm{~Pa}$ at gas temperature of $300 \mathrm{~K}$. Obviously, a pressure of $0.0 \mathrm{~Pa}$ is a unphysical situation, but shows the transport of sputtered atoms in the absence of sputtering gas. The interaction potential used between metal and Ar atoms was the screened Coulomb potential with a Molière function. SiMTra requires some inputs, in particular, the racetrack profile of the target and the nascent angular and energy distributions. The racetrack profile was obtained from the target used in laboratory by confocal microscopy technique. The nascent angular and energy distributions were calculated for $\mathrm{Gd}$ and $\mathrm{Ti}$ by using the software SRIM ${ }^{16}$ for argon ions with energy of $470 \mathrm{eV}$ and normal incidence to the target. The angular distribution of Gd and Ti are similar in shape. The simulations for Ti that included only the grid were performed also using the Thompson energy distribution ${ }^{17}$, as made by Depla and Leroy ${ }^{9}$. For these simulations, the angular distribution is obtained from the expression developed by Zhang et al. ${ }^{18}$ The expression provides six coefficients used in SiMTra to describe the distribution. In these simulations, the default conditions provided by SiMTra were used.

Table 1 shows a scheme of simulations. In the simulations A, $\mathrm{B}$ and $\mathrm{C}$ there is no anode in front of the target. In simulations $\mathrm{D}$ and $\mathrm{E}$, the grid anode was used and the grid-target distance was set to $23 \mathrm{~mm}$. The deposition was analyzed in the substrate holder with a diameter of $100 \mathrm{~mm}$. In the $\mathrm{D}$ case, simulations were also done by admitting a constant pressure of $0.4 \mathrm{~Pa}$ and by varying the grid-target distance from 10 to $40 \mathrm{~mm}$.

Table 1: Schematic of simulations.

\begin{tabular}{|c|c|c|c|}
\hline Geometry & $\begin{array}{c}\text { Surface } \\
\text { analyzed }\end{array}$ & SRIM & Thompson \\
\hline $\begin{array}{c}\text { No grid, no } \\
\text { shutter and no } \\
\text { disk }\end{array}$ & $\begin{array}{c}\text { Substrate } \\
\text { holder } \\
\text { Sample }\end{array}$ & A & B \\
\hline Grid & $\begin{array}{c}\text { Substrate } \\
\text { holder }\end{array}$ & D & E \\
\hline Shutter & $\begin{array}{c}\text { Sample } \\
\text { Sample }\end{array}$ & F & \\
\hline Gid and shutter & $\begin{array}{c}\text { Sample } \\
\text { Disk anode }\end{array}$ & $\begin{array}{c}\text { Substrate } \\
\text { holder }\end{array}$ & H \\
\hline
\end{tabular}

To analyze the interference in average energy caused by a shutter close to a substrate (Fig. 1a), a sample was simulated. The sample is a circular piece with a diameter of $19 \mathrm{~mm}$ located on substrate holder (simulations $\mathrm{G}$ and $\mathrm{H}$ ) at $37.5 \mathrm{~mm}$ from the center. The sample was also used only with the grid (simulation F).

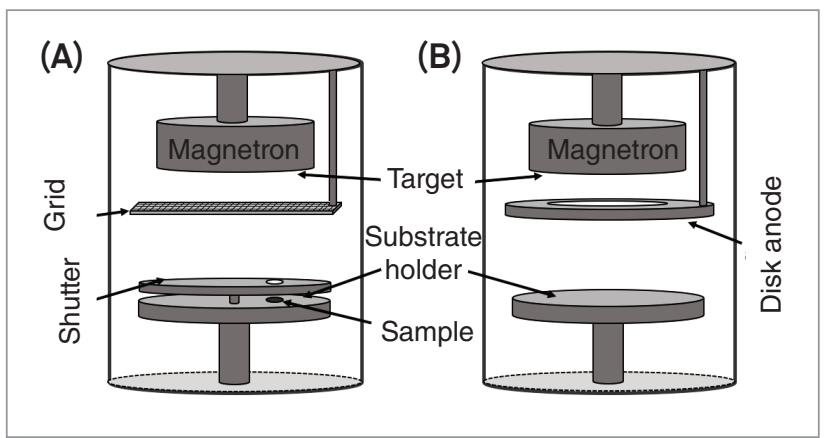

Figure 1: Chamber geometry $(A)$ the grid and shutter; $(B)$ the disk anode. 
The disk anode was used in simulation I (Fig. 1b). The anode, at $23 \mathrm{~mm}$ from the target, is a circular plate with an external diameter of $110 \mathrm{~mm}$ and an aperture in the center. Three aperture diameters were used: 20,40 , and $60 \mathrm{~mm}$. In each condition the deposition of $10^{6}$ sputtered atoms was simulated, this quantity is large enough for statistical analysis of the process.

\section{RESULTS AND DISCUSSIONS}

\section{Grid anode}

It can be seen, in Fig. 2, the average energy of deposited atoms ( $\mathrm{Gd}$ and $\mathrm{Ti}$ ) at the substrate holder according to the simulations $\mathrm{A}$ and $\mathrm{D}$. The average energy decreases with increasing argon pressure, due to the higher number of collisions between sputtered atoms and gas atoms. It is noted that the introduction of the grid increases the average energy of deposited atoms for both targets. This effect is more pronounced for $\mathrm{Ti}$ in the range between 2.0 and $5.0 \mathrm{~Pa}$.

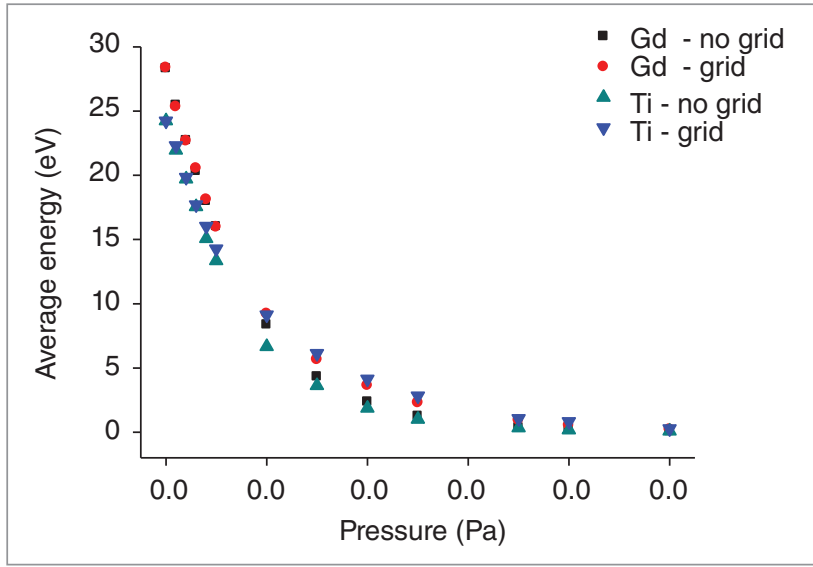

Figure 2: Average energy of deposited atoms in the substrate holder as a function of pressure with and without grid.

A similar trend is observed in simulations B and E, where the Thompson energy distribution was used. However, in these cases, the average energy is smaller than when using the distribution obtained by SRIM. The Thompson distribution considers a cut-off energy for the sputtered atoms $(132.91 \mathrm{eV}$ for Ti). This causes a larger population of high energy sputtered atoms in SRIM, rising the average energy of deposited atoms. However, in both cases a small increase of average energy of deposited atoms with the grid is observed.

Between 1.0 and $8.0 \mathrm{~Pa}$ it is possible to observe, by the normalized energy distribution function of deposited atoms (Fig. 3), that without grid the population of high energy atoms is lower, decreasing the average energy. A difference in average energy was observed also on simulations F, G, and H (Fig. 4). The average energy is higher when the shutter is considered, and even greater with both pieces (grid and shutter). It must be pointed out that statistically the number of deposited atoms on sample is low, if compared to the substrate holder in the previous simulations, especially to $8.0 \mathrm{~Pa}$, where only $0.05 \%$ of sputtered atoms are deposited on the sample.

Figure 4 shows the normalized energy distribution of titanium atoms deposited on sample at $2.0 \mathrm{~Pa}$ (simulations $\mathrm{C}, \mathrm{F}, \mathrm{G}$, and $\mathrm{H}$ ). A part of sputtered atoms is deposited on the surfaces nearest the target. As the low energy population is larger than the high energy population, it is more probable that low energy atoms deposit on grid (or on shutter) than high energy atoms. Consequently, this reduces the population of low energy atoms that reach the sample, increasing the average energy. Thus, when added both the grid and the shutter, a significant fraction of low energy atoms deposit on these surfaces, increasing the average energy of deposited atoms on sample. By introducing more pieces between the target and the sample, the increase in average energy is greater. However, the total energy transferred to sample tends to decrease, due to the reduction in number of deposited atoms. For $0.4 \mathrm{~Pa}$, the total energy transferred to the sample by deposited $\mathrm{Ti}$ atoms decreases from $207 \mathrm{keV}$ to $137 \mathrm{keV}$, when the grid is introduced.

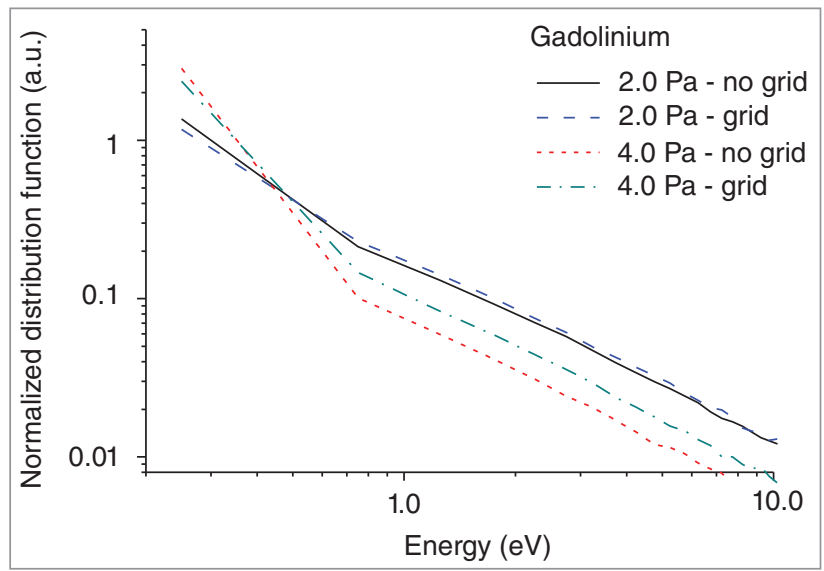

Figure 3: Normalized energy distribution for gadolinium atoms, with and without grid at pressures 2.0 and $4.0 \mathrm{~Pa}$, using the energy distribution of SRIM.

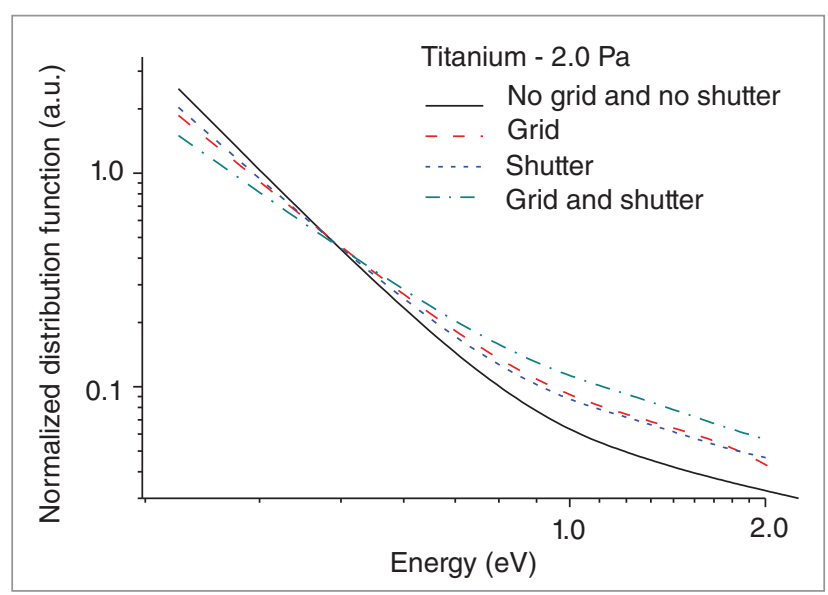

Figure 4: Normalized energy distribution for titanium atoms deposited on sample, at $2.0 \mathrm{~Pa}$, using the energy distribution of SRIM. 
In the same way, for $2.0 \mathrm{~Pa}$, the total energy decreases from 67 $\mathrm{keV}$ to $45 \mathrm{keV}$.

At low pressures $(<1.0 \mathrm{~Pa})$, the difference in average energy is lower (Fig. 2). Increasing the pressure, there is a high number of collisions in gas phase, which increases the population of low energy atoms. Thus, for low pressures, the probability of deposition of a low energy atom on the grid (or shutter) is not so high, if compared to a high energy atom. For high pressures, the atoms are thermalized when they reach the substrate. Therefore, above $8.0 \mathrm{~Pa}$ there is not an appreciable variation in the average energy (Fig. 2). The simulations varying the grid-to-target distance (D) show that the distance does not interfere in the effect caused by grid, and the average energy is almost the same for all distances.

\section{Disk anode}

With simulation I, it was possible to observe that the anode geometry interferes in the average energy (Table 2). To analyze such interference, simulations were performed by including a plane in the anode position, and by studying the energy profile in this plane and in the substrate holder (Fig. 5).

Table 2: Average energy of gadolinium atoms deposited on substrate holder at 0.4 and 2.0 $\mathrm{Pa}$ for different aperture sizes of disk anode and without it.

\begin{tabular}{|c|c|c|}
\hline \multirow{3}{*}{$\begin{array}{l}\text { Aperture diameter } \\
\qquad(\mathrm{mm})\end{array}$} & \multirow{2}{*}{\multicolumn{2}{|c|}{$\begin{array}{c}\text { Gadolinium } \\
\text { Average energy (eV) }\end{array}$}} \\
\hline & & \\
\hline & $0.4 \mathrm{~Pa}$ & $2.0 \mathrm{~Pa}$ \\
\hline 20 & 22.95 & 8.58 \\
\hline 40 & 22.83 & 9.72 \\
\hline 60 & 22.98 & 10.03 \\
\hline No anode & 22.73 & 8.36 \\
\hline
\end{tabular}

It can be seen that the energy of deposited atoms is higher on the anode than on the substrate, due to the lower target-anode distance, which implies in less collisions in the trajectory from target to anode. At the anode, the energy profile is uniform, while at the substrate holder the energy of deposited atoms is higher at the center, once that only the atoms that pass through the disk aperture reach the substrate holder.

The effect of disk anode on average energy is, therefore, similar to the effect of the grid. The average energy is almost the same for all the aperture sizes at $0.4 \mathrm{~Pa}$, but increases with disk aperture at 2.0 $\mathrm{Pa}$ (Table 2). At this pressure, low energy atoms are deposited on the edge of the disk anode (Fig. 5a), reducing the low energy atom population that reaches the substrate holder. However, for small apertures, high energy atoms are also deposited on the disk. Thus, the increase in average energy, relative to the case without anode, is less pronounced.

\section{CONCLUSION}

The simulations done using the software SiMTra show that the average energy of deposited atoms can be shifted by changing the anode geometry. In all simulations, this shift is more relevant in high pressures $(1.0-6.0 \mathrm{~Pa})$ when compared to conventional pressures used in magnetron sputter deposition $(<1.0 \mathrm{~Pa})$. From the simulations, it can be concluded that the increase in average energy can be done by "trapping" low energy atoms, avoiding their deposition on substrate. However, it must be pointed out that this strategy reduces the deposition rate and the total energy transfer to the substrate. Besides, the change in average energy calculated is, in general, quite small to produce considerable effects on growing films.

\section{ACKNOWLEDGMENTS}
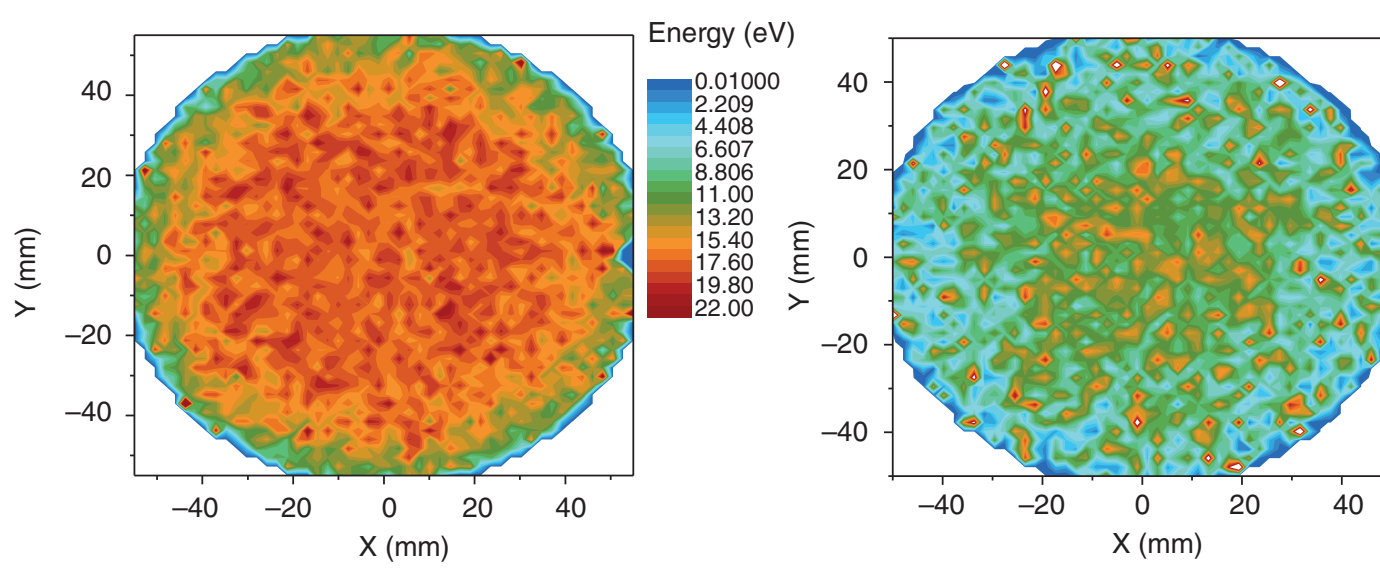

Energy (eV)

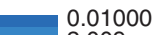
2.009 4.008 6.007 8.006 10.00 12.00
14.00 16.00
18.00 20.00

Figure 5: (A) Energy profile of gadolinium atoms deposited on the plane inserted in anode position; (B) the energy profile of atoms deposited on the substrate holder, using an anode with aperture diameter of $40 \mathrm{~mm}$ at $2.0 \mathrm{~Pa}$. 
The financial support of Brazilian agency program MCTI/ CNPQ/Universal (grant $n^{\circ}$ 455896/2014-3) and PAP-UDESC/ FAPESC are strongly acknowledged.

\section{REFERENCES}

1. Kersten $\mathrm{H}$, Deutsch $\mathrm{H}$, Steffen $\mathrm{H}$, Kroesen GMW, Hippler R. The energy balance at substrate surfaces during plasma processing. Vacuum. 2001;63(3):385-431. Available from: http:// dx.doi.org/10.1016/s0042-207x(01)00350-5

2. Fontana LC, Muzart JLR. Characteristics of triode magnetron sputtering: the morphology of deposited titanium films. Surface and Coatings Technology. 1998;107(1):24-30. Available from: http://dx.doi.org/10.1016/s0257-8972(98)00576-3

3. Trushin OS, Kokko K, Salo PT. Film-substrate interface mixing in the energetic deposition of $\mathrm{Ag}$ on $\mathrm{Cu}(001)$. Surface Science. 1999;442(3):420-430. Available from: http://dx.doi.org/10.1016/ s0039-6028(99)00955-3

4. Fontana LC, Muzart JLR. Triode magnetron sputtering TiN film deposition. Surface and Coatings Technology. 1999;114(1):7-12. Available from: http://dx.doi.org/10.1016/s0257-8972(99)000328

5. Sagás JC, Fontana LC, Maciel HS. Influence of electromagnetic confinement on the characteristics of a triode magnetron sputtering system. Vacuum. 2011;85(6):705-710. Available from: http://dx.doi.org/10.1016/j.vacuum.2010.11.002

6. Sagás JC, Pessoa RS, Maciel HS. Langmuir probe measurements in a grid-assisted magnetron sputtering system. Brazilian Journal of Physics. 2018;48(1):61-66. Available from: http://dx.doi. org/10.1007/s13538-017-0539-3

7. Sagás JC, Duarte DA, Irala DR, Fontana LC, Rosa TR. Modeling reactive sputter deposition of titanium nitride in a triode magnetron sputtering system. Surface and Coatings Technology. 2011;206(7):1765-1770. Available from: http:// dx.doi.org/10.1016/j.surfcoat.2011.07.013

8. Belkind A, Jansen F. Anode effects in magnetron sputtering. Surface and Coatings Technology. 1998;99(12):52-59. Available from: http://dx.doi.org/10.1016/s02578972(97)00409-x
9. Depla D, Leroy WP. Magnetron sputter deposition as visualized by Monte Carlo modeling. Thin Solid Films. 2002;520(20):63376354. Available from: http://dx.doi.org/10.1016/j.tsf.2012.06.032

10. Van Aeken K, Mahieu S, Depla D. The metal flux from a rotating cylindrical magnetron: a Monte Carlo simulation. Journal of Physics D: Applied Physics. 2008;41(20):205307. Available from: http://dx.doi.org/10.1088/0022-3727/41/20/205307

11. Mahieu S, Buyle G, Depla D, Heirwegh S, Ghekiere P, De Gryse R. Monte Carlo simulation of the transport of atoms in DC magnetron sputtering. Nuclear Instruments and Methods in Physics Research Section B: Beam Interactions with Materials and Atoms. 2006;243(2):313-319. Available from: http://dx.doi. org/10.1016/j.nimb.2005.09.018

12. Horkel M, Van Aeken K, Eisenmenger-Sittner C, Depla D. Mahieu S, Leroy W. Experimental determination and simulation of the angular distribution of the metal flux during magnetron sputter deposition. Journal Of Physics D: Applied Physics. 2010;43(7):075302. Available from: http://dx.doi. org/10.1088/0022-3727/43/7/075302

13. Siad A, Bernard A, Nouveau C, Jacquet P. Critical angles in DC magnetron glad thin films. Vacuum. 2016;131:305-311. Available from: http://dx.doi.org/10.1016/j.vacuum.2016.07.012

14. Strijckmans K, Depla D. A time-dependent model for reactive sputter deposition. Journal of Physics D: Applied Physics. 2014;47(23):235302. Available from: http://dx.doi. org/10.1088/0022-3727/47/23/235302

15. Depla D. On the effective sputter yield during magnetron sputter deposition. Nuclear Instruments and Methods in Physics Research Section B: Beam Interactions with Materials and Atoms. 2014;328:65-69. Available from: http://dx.doi.org/10.1016/j. nimb.2014.03.001

16. Ziegler JF, Biersack JP, Ziegler MD. SRIM - The Stopping and Range of lons in Matter [internet]. Available from: www.srim.org

17. Thompson MW. Atomic collision cascades in solids. Vacuum. 2002;66(2):99-114. Available from: http://dx.doi.org/10.1016/ s0042-207x(02)00179-3

18. Zhang ZL, Zhang L. Anisotropic angular distribution of sputtered atoms. Radiation Effects dnd Defects in Solids. 2004;159(5):301307. Available from: http://dx.doi.org/10.1080/104201504100017 24495 